\title{
The A.C.R.L. and the Statistics Program of the Office of Education'
}

\author{
Dr. Purdy is librarian, Wayne Univer- \\ sity.
}

$\mathrm{T}^{\mathrm{N}}$ His presidential address at the St. Louis 1 Conference of the A.L.A. in 1889 Charles A. Cutter said:

I cannot help regretting the amount of time that is wasted on statistics. They are interesting, but they are costly to prepare and to print, and I would rather see the time spent on making the library more useful. ${ }^{2}$

Like most quotations out of context, this one is unfair to its author, who went on to qualify his position. I exhume it for you because it summarizes succinctly an attitude with which most of us here today are familiar, and even more or less sympathetic, notwithstanding the attention we devote to statistics, and the enlarged meaning of the term. To Mr. Cutter, the word meant simply numerical facts about libraries. To us it means both the quantitative facts and the mathematical techniques for determining and describing their meaning-techniques largely unknown in 1889 .

It cannot be denied that our generation of librarians as well as Mr. Cutter's, has reason to view statistics with skepticism. Statisticians, or rather pseudo statisticians, in the social sciences have given statistics a bad name which the technique, or science if you will, does not deserve. They have naïvely claimed, or implied, that nothing which is not measurable is real; that no

1 Paper presented at the meeting of the A.C.R.L., Chicago, Jan. 30, 1948 .

2 Cutter, Charles A. "Common Sense in Libraries." A.L.A. Papers and Proceedings of the Ioth General Meeting... I 889 . p. I-8; quotation on p. 2 . phenomenon, whether physical or spiritual, is immune from quantitative analysis; that understanding follows automatically on the heels of measurement; that understanding without measurement is unthinkable, indeed, almost, that thought itself is impossible outside the realm of measurement and measurable phenomena. They have often failed (or refused) to recognize that only a few phenomena can be measured, to date, and hence that relatively few facts are quantitative; that the mere statement of an alleged fact in quantitative terms does not make it a fact; that even facts which can be defined quantitatively are meaningless except as raw materials with which to think, and hence that statistically-achieved conclusions are determined no less by the statistician's assumptions and inferences than by the nature of his facts and the technical analysis to which he subjects them.

But to admit the human fallibility of statisticians is not to deny the necessity of measuring the significant phenomena which are measurable or of using the logical techniques which the mathematicians have given us, as well as other logical methods, in our effort to understand their meaning. Many facts about libraries and librarians, about library service and the people whom libraries exist to serve, can be described accurately in terms of quantitative units. In short, at least a few of the phenomena which librarians need to understand are measurable. We cannot hope to grow in social effectiveness unless we try to understand these phenomena, as well as the admittedly 
more important facts and assumptions which fall, for example, in the realm of values.

There is nothing new in this position, of course. From their genesis, the A.L.A. and its affiliated organizations have recognized the potential value of quantitative facts pertinent to the valuation and improvement of library service. Many hours of intelligent effort have been devoted to the identification of those data which are most useful, and to their standardization-not to mention collection and reporting. In 1877 the A.L.A. Cooperation Committee said, in its fifth report:

The great diversity in the arrangement of library statistics, as presented in the annual reports of the ... libraries of the country, suggests to every inquirer into the "true inwardness" of these institutions the advantages that would accrue to all interested parties from the adoption by all libraries of uniform tables for statement of receipts and expenses, and also the statistics of circulation, acces- $\checkmark$ sion, and general library work. Uniformity of headings is necessary for comparison between libraries, as well as to obtain true averages in various departments of work. With this in view, the following model for statistical reports has been prepared, as covering, to a great extent, the principal features of library work. ${ }^{3}$

The list which followed was surprisingly comprehensive. It included most of the data collected on recent A.L.A. and Office of Education forms, with no little additional detail. In September of the same year the proposed form was adopted by the A.L.A., with some modification. ${ }^{4}$

In 1903 to 1906 the Committee on $\mathrm{Li}$ brary Administration developed a new form, or rather three forms, which were printed in the proceedings of the 1906 conference. $^{5}$ A revised form was adopted in

\footnotetext{
${ }^{3}$ A.L.A. Cooperation Committee. "Library Statistics." Library Journal I: 429-3I, Aug. 3I, 1877 .

${ }_{4}^{4}$ Library Journal 2: $37-38$, September 1877 .

5 A.L.A. Papers and Proceedings of the 28 th General Meeting... 1906. p. 146-53.
}

1915. In each instance uniformity was the chief objective.

In November of 1928 Charles B. Shaw read a paper at the fifteenth conference of eastern college librarians, in which he deplored the lack of uniformity in library statistics and recommended the appointment of a committee of the A.L.A. to deal with the problem. ${ }^{6}$ The College and Reference Section appointed such a committee, under the chairmanship of Julian S. Fowler. This committee reported the following May at the West Baden meeting with copies of a proposed form for collecting college and university library statistics, which was subsequently used to collect the facts reported in the first and second yearbooks of the College and Reference Section. The following year a radically different form was used.

At the Washington conference in 1929 , the A.L.A. Council adopted a resolution:

Recognizing the need of a research and statistical department in the A.L.A. . . . the Council recommends that the Executive Board take action looking toward such establishment at the earliest possible time.... (The Survey Committee in December I929, had adopted a similar resolution.) ${ }^{7}$

In December of 1933 George F. Bowerman, in his capacity as chairman of the Committee on Library Research Bureau at Headquarters, presented a specific proposal and budget which resulted in the addition of a statistical assistant to the Headquarters staff in 1934. A modest statistical service was maintained there for eight years-until wartime pressures upon the A.L.A. budget, combined with shrinking revenues, allegedly necessitated first curtailment and later discontinuance of the service. We are all too familiar with the result.

For at least three years the A.L.A. Sta-

\footnotetext{
- Shaw, Charles B. "Statistics-Uniform or Motley." Libraries 34: 89-90, February 1929.

${ }^{7}$ A.L.A. Bulletin 25: 297, August 1929 .
} 
tistics Committee has sought other means of making available to librarians the quantitative facts which they want and need. For approximately two years the committee has awaited the formulation of a definite program by the U. S. Office of Education, since a coordinated program appeared to be an obvious necessity. That Office of Education program, insofar as it is concerned with college and university library statistics, has been described to us in the preceding paper. We are now in a position to consider a complementary program.

The first "major activity" described by Mr. Dunbar is "a comprehensive collection and publication of college and university library statistics once every four years on as uniform a pattern as possible." The word "comprehensive" obviously refers to the institutions to be covered rather than to the facts to be collected or published. The form to be used will be essentially the same in content as that used for the collection of 1939-40 data and for recent annual A.L.A. collections. A few additions and omissions are contemplated. Specifically, questions concerning audio-visual materials (holdings, use, and expenditures) have been added and the following items have been dropped: breakdown of holdings by branch, income data, daily schedule breakdown, staff training data, and special enrolment data (extension and correspondence students). I see little reason to regret any of these proposed omissions.

No salary data will be collected in the quadrennial survey, but a special salary study is projected for the immediate future. Thus the facts collected each fourth year will be essentially the same as those which the A.L.A. has collected annually. The coverage of libraries will be comprehensive, which is a vast improvement, but the facts to be published will be fewer than those heretofore published in the A.L.A. Bulletin and, more recently, in College and Research Libraries. If the A.L.A. and the A.C.R.L. were to rely entirely upon the Office of Education, the net result would be a gain in research data available (by reason of comprehensive coverage) but a serious loss to library administrators, at least for the present, in frequency and in scope of information published.

The preliminary releases will be invaluable, as were those covering public libraries last year, but likewise inadequate in inclusion of facts and in frequency of appearance. The projected salary study will also be invaluable. The proposed technique represents a vast improvement, in every respect, I submit, over that used in collecting and reporting the traditional A.L.A. salary statistics. But again, the facts which will be made available are facts which should be collected and published every year, particularly in periods of rapid economic change. It is possible that the Office of Education may be able to collect them annually, or biennially, but we cannot count on them at this stage.

The facts collected and reported in the biennial survey in the past are of relatively little use to librarians. Occasional special studies of the Division of Higher Education will be useful, and doubtless we should encourage more of them.

The potential statistical program which Mr. Dunbar has described demonstrates a real grasp of the total problem and genuine vision in projecting a solution. After listening to Mr. Dunbar's account of the difficulties involved in executing such a program, I must confess that I am pessimistic about the immediate prospect. I think I have learned from $\mathrm{Mr}$. Dunbar and $\mathrm{Mr}$. Mishoff that the total job is, at present, too big for any one existing agency. Indeed, I began to realize two years ago that this is the case. The present program of the 
Office of Education provides us with a reasonably clear picture of the job which remains to be done: We need certain quantitative facts annually and promptly following the period which they describe. We may be able eventually to persuade those who control the Office of Education budget to make it possible for the Service to $\mathrm{Li}$ braries Section to do the whole job for us, but meantime, if we want annual statistics we will probably have to collect and publish them.

I therefore suggest that the A.C.R.L. appoint immediately a committee on statistics, whether entirely autonomous or conceived as a subcommittee of the A.L.A. Statistics Committee, to draft a concrete plan for a statistics program for the association, for presentation at Atlantic City. Any plan which such a committee may present will necessarily be supplementary to and carefully integrated with the program of the Office of Education. If I may presume to outline the task of such a committee, I should suggest the following steps:

I. The compilation of comprehensive checklists of useful statistics for university, college, junior college, and reference libraries. Some such lists have been compiled and their revision for a specific purpose would not be too difficult.

2. The submission of these checklists to librarians for their vote as to those required annually, biennially, etc., and those more suitable for occasional special studies rather than for regular collection.

3. The construction of a tentative form for the annual collection, for each type of libraries or for all types of libraries represented in the A.C.R.L.- also perhaps forms for less frequent or irregular or special collection.

4. Consultation with Office of Education and other government officials to determine how much of the job, beyond its present program, that office can do for us.

5. Revision of forms to eliminate duplication.

6. The construction of lists of libraries to which the proposed forms should be regularly sent.

7. Formulation of a concrete and practicable plan for collecting, compiling, analyzing, and publishing the required facts.

'The last step is the difficult one, of course, but presents no insoluble problem, I am convinced. Assuming that publication in College and Research Libraries is practicable, the remainder of the job can be done on a cooperative, volunteer basis, if necessary.

The proposed committee may also want to consider the practicability of a selfsupporting statistics service maintained on a subscription basis. The A.L.A. Council suggested such a plan for the collection and publication of statistics for all types of libraries in 1929. In 1945 the A.L.A. Publishing Department and the A.L.A. Statistics Committee drafted a proposal for such a self-supporting subscription-basis service, which proposal was shelved pending definition of the U.S. Office of Education program. Personally, I doubt the practicability of a self-supporting service, but possibly your committee, if one is appointed, can find a way to make one work.

In short, the proposed committee would serve two important purposes: Implementation of the potential program of the Service to Libraries Section of the Office of Education, and development of a short-term and a long-term complementary program for the A.C.R.L. 